\title{
FORUM
}

\section{Single-handed Voyages and the Collision Regulations}

The 1972 Collision Regulations, which came into force in July 1977, strengthen the injunction on all vessels to keep a proper lookout by making it the subject of a separate Rule rather than including it in a general statement relating to the ordinary practice of seamen. The old Rule which laid down that nothing in the Rules would exonerate any vessel from the consequences of (amongst other things) 'any neglect to keep a proper lookout' virtually left what constitutes a proper lookout to the Courts. Rule 5 of the 1972 Regulations is much more specific. It reads: 'Every vessel shall at all times maintain a proper lookout by sight and hearing as well as by all available means appropriate in the prevailing circumstances and conditions so as to make a full appraisal of the situation and the risk of collision'. The Regulations apply in effect to 'every description of water craft' although it is reasonable to suppose from their source that the kind of vessel most in mind, unless otherwise stated, is the power-driven ship rather than, say, sampans or dugout canoes.

There can be little doubt that the practice of single-handed sailing over long distances brings into question whether in these circumstances Rule 5 is being observed. Those who hold that it is not will say that a man cannot be on watch and asleep at the same time. Others may say that the wording of the Rule relates to the risk of collision and that it is perfectly possible to maintain a full lookout where shipping is likely to be encountered and relax it where the risk of collision is negligible. How single handers in fact conduct themselves at sea is therefore much to the point.

If single-handed sailing ipso facto breaches the Collision Regulations (a matter that is currently under discussion at Imco), then in principle the simplest thing would be to forbid it. Yet, practical difficulties aside, unless it can be shown that such a step is in fact contributing to safety at sea, there would be many to regret it, not least among the seafaring community. Illustrious figures like Chichester and Tabarly have caught the imagination of the public and done much to spread the practice of navigation and good seamanship, particularly amongst the young.

In order to illuminate some of the issues, the Institute has invited comment from Members and others who have been closely concerned in one way or another with the problem of collision at sea and with single-handed voyaging. Commander L. R. R. Foster, R.N. (ret.) is Sailing Secretary of the Royal Western Yacht Club of England which organizes the Observer Single-handed Transatlantic Race (OSTAR); H. G. Hasler, who writes from his long experience of single-handing, was the originator of OSTAR: J. D. Sleightholme is Editor of Yachting Monthly which is responsible for one of the major single-handed events in the United Kingdom (Azores \& Back); Captain A. N. Cockcroft is co-author, with J. N. F. Lameijer, of $A$ Guide to the Collision Avoidance Rules; and Captain Arnout Wepster is Director of the Navigation Research Centre at the Netherlands Maritime Institute. 


\section{from Commander L. R. R. Foster}

Rule 2 of the Rules and Conditions of entry for the Singlehanded Transatlantic Race reads as follows (and has always done so) :

'The Race is intended to be a sporting event, and to encourage the development of suitable boats, gear, supplies and technique for single-handed ocean crossings under sail.'

As originally conceived the race was for yachts of moderate size sailed by experienced yachtsmen who would interfere with no one and be a danger only to themselves. To encourage originality and ingenuity as few rules and restrictions as possible were made with the result that in 1976 a fleet of 125 yachts ranging from 24 feet to 236 feet LOA came to the starting line.

Much has been said and written about the Committee's decision to allow the 236 foot Club Méditerannée to take part, but suffice it to say that in the event most of the problems of the race stemmed from the unusually atrocious weather which competitors on the northern route experienced.

The results showed that biggest is not necessarily best and it is a feature of the series of races that this fact has been shown in practice to be so and it is with that experience behind us that we can now settle down to a race in which size will be restricted. Collision danger apart a higher upper limit than the present 56 feet LOA would be preferred, perhaps $6{ }_{5}$ feet, but the limit now imposed will ensure a situation in which competitors are not a serious danger to anybody but themselves as far as collision is concerned.

Although sadly two competitors were lost in the: 1976 race, and other competitors in this and other races have been injured, no one other than a competitor has been injured and it is the Committee's intention to do all they can to keep it this way. Those who take part in the OSTAR are no ordinary yachtsmen; they have an extraordinary ability to remain awake for long periods and catnap when in restricted waters.

The race is run once every four years by a Committee consisting of experienced ocean going yachtsmen and professional seamen whose every endeavour is directed to making the event a responsibly organized one, as safe as such an event can be. The fact that it remains a hazardous enterprise is fully recognized but does not mean that it should not take place, any more than danger is a reason for inhibiting other forms of sport. Indeed the element of danger and the sense of achievement are its main attractions and rightly so in a world where courage and endurance are still; we hope, applauded.

It may be of interest to quote from the conditions of entry for the race the rules which deal with evidence of the fitness of the boat and skipper to undertake such a voyage:

'8.1 Before making his application the entrant must have completed a singlehanded qualifying cruise of not less than 500 miles of open sea without anchoring or putting into port. The 500 miles must be measured in straight lines between not more than four fixes, and must be made in the yacht which he will sail in the Race. He may not be escorted at any stage by any other yacht or vessel.

8.2 In addition, each yacht must have done a cruise of not less than 1000 miles with the prospective entrant on board but not necessarily by himself. This cruise must reach a distance of at least 300 miles from its starting point 
and must consist of openwater sailing, but may include any number of stopping places.

8.3 A crew who has been an official finisher in a previous Single-handed Transatlantic Race is only exempted from requalifying if he is sailing the same yacht as before and without substantial alteration to the yacht.

8.4 Owing to the danger to navigation, single-handed passages in congested areas will not be acceptable. Cruises should be planned to avoid shipping lanes, and sailing in pilotage waters restricted to the time that the crew can keep a proper look out.'

There will always be yachtsmen who will cross oceans by themselves. If they get the urge out of their system by doing so in an organized event, arranged at four yearly intervals and supervised as regards their yacht's condition, equipment and skipper's ability, the event will have served a good purpose on that score alone.

\section{from H. G. Hasler}

Rule 5 of the 1972 Regulations seems to be anything but specific. Does it mean that there has to be at least one man on watch who is a lookout and nothing else? or does it mean that this man can also be steering, navigating, shaking the next watchkeeper, and so on? In either case, does it envisage that 'a proper lookout by sight and hearing' can be kept through the windows of a wheelhouse (an absurd contention on a dark night with pelting rain and internal machinery noises), or are we about to return to the days when a lookout stood out in the weather for four hours non-stop, preferably right forward ? Many yachtsmen will feel that the lookout kept by many power vessels has been shown to be far less adequate than that of the average single-hander. Has there been any impartial investigation into what lookout merchant vessels, particularly small coasters and fishing boats, actually keep ? It is not enough to tell them that they are legally in the wrong if they don't keep a lookout. They should be told what sort of lookout they are supposed to be keeping, and this would no doubt have to be agreed by the seamen's unions.

In my opinion, the art of single-handing is based, first, on the art of catnapping. I am assisted in this by a kitchen timer which is often set for less than 5 minutes when close to shipping or other hazards. A trained single-hander (it is sometimes overlooked that it does need training) can maintain full mental and physical efficiency for an unlimited number of days without ever sleeping for more than about 20 minutes at a time-often for only a half a minute--but these catnaps must be taken at very frequent intervals throughout the 24 hours, and must be started as soon as he leaves port, long before he begins to feel tired. On the rare occasions when he cannot even lie fully clothed on his bunk for five minutes, the good single-hander learns to nod for a few seconds at a time while actually on watch, and finds that after doing this ten or twenty times he feels less sleepy. The medical aspects of catnapping versus fatigue have not, I think, been properly investigated.

The second attribute of a good single-hander is the ability to conserve energy by not allowing himself to worry about anything other than an immediate problem, and by not doing any unnecessary work unless his situation is so free from problems that boredom sets in, as may well be the case on a long ocean crossing. Unnecessary navigational work is a prime offender, possibly because so many 
yachtsmen work in offices that it seems natural to them to work in an office in a singlehanded five-tonner. Three quarters of the navigational work done by the average yachtsman is unnecessary, and would not have been done by a professional fisherman in the days of sail. Trying to do it all in a small boat bucketing around in the middle of a dirty night is a certain recipe for exhaustion.

The same is true of the thousand jobs around the boat that nag at the mind of a good ship's husband. Only those that are essential for seaworthiness should be tackled while the boat is in coastal waters or shipping lanes; the rest must be put firmly out of mind, or on to a list of occupational therapy reserved for days when everything is relaxed and free from danger.

\section{from J. D. Sleightholme}

ThE Collision Regulations provide a framework within which all seamen seek to handle their vessels safely; but it is accepted and allowed for in the Rules themselves that it is the man and not the Rule which has the ultimate responsibility for avoiding collision. A man in charge who has the experience, the coolness and the ability to make a rapid and perhaps radical decision and to act upon it ance must many times have averted collision and not infrequently had to act upon Rule 17.

This points to a need for a high degree of professionalism but even more does it point to those human qualities which professionalism alone does not guarantee. Among yachtsmen it is all too often apparent that neither professionalism nor the quick wits and nerve of the instinctive seaman are present. The mounting record of lifeboat rescues indicates a lack of resourcefulness too among people who could well help themselves were they but more self-reliant, experienced or not. This resourcefulness, self-reliance and instinctive gut-reaction to a crisis cannot be taught, although it can be cultivated in those who are psychologically fitted to it. Such people are self-selecting. It is a mark of the true single-hander that he (or indeed she) is motivated by self-reliance in the first place, and he will not long remain a singlehander unless resourcefulness and gut.-reaction in crisis materialize in the course of things.

There are those among the 'lone sailor' ranks who are incompetent and dangerous cranks who neither plan nor reason. Such people exist in every walk of life, every sport and in every society. They will always be there and neither legislation nor persuasion will rid us of them; they must be accepted as perpetual fools and regarded as a 'factor $X$ ' to be dealt with or disregarded. They are not typical of yachtsmen, or even of people.

There can be no question that the single-handed yachtsman who is at sea for long enough to require to sleep will disobey the letter of Rule 5 ; he cannot maintain a proper lookout at all times. A proper lookout must be defined as a ceaseless scanning of the whole horizon by an alert and responsible person and anything less than this is not proper lookout; indeed, by virtue of being a lookout in name only, there is a greater danger imposed. A poor lookout may seem better than none; in fact a poor lookout constitutes a real threat since it may cause a relaxation among other members of a crew, who would otherwise be alert. And in terms of the Rules a poor lookout does not constitute a proper one, for he is unable to supply the sort of information (Rule 5) that "allows a full appraisal of the situation'. Thus Rule 5 will be 'stretched' again and again, not only by the sleepy second hand on the coaster and passage-making fishing vessel but inevitably on the big commercial vessel also. 
Which of two evils is the greater, the single-hander who elects to sleep during daylight, or in very short spells, or in areas where other shipping is thin on the ground and who is well aware of the risks and subconsciously tuned to them, or the lookout (be he yachtsman or ship crew), who yawns his way through an interminable watch oblivious to most of what is going on and interested only in the passage of time? It is my belief that a proper lookout in the full and intended meaning of the term is a rarity.

Single-handing a yacht calls for imagination and great foresight, skill in seamanship and conservation of stamina. Show me a dedicated singlehander and I will show you the man I would trust in an emergency. If the sport of single-handed sailing expands, as it appears to be doing, the overall result will be an improvement of standards among all offshore sailing people. The presence in any yacht crew of an erstwhile singlehander will ensure that his watch at least is infused with higher standards, and the standard will spread.

\section{from Captain A. N. Cockcroft}

Every vessel is now specifically required by Rule 5 of the 1972 Collision Regulations to keep a proper lookout by sight and hearing at all times, but this is not really an extension of the previous requirement. The Courts have always interpreted the old Rule 29 as having the same meaning as that explicitly stated in the new Rules.

The degree of vigilance which is necessary in order to keep a proper lookout must obviously be related to the probability of encountering other vessels. Some relaxation is justified in the open ocean. The responsibility for maintaining a good lookout should also be greater for large, fast ships than for small craft as the former are generally required to keep out of the way of other vessels and the consequences of a collision could be serious. A small yacht is unlikely to cause appreciable damage or inconvenience to a ship with which it collides.

However, the Rules do apply to every description of water craft, regardless of . size. A person in charge of a small yacht may not be required to take avoiding action when a power-driven vessel approaches so as to involve risk of collision but does have the responsibility to see that the navigation lights are conspicuously displayed, to attempt to attract attention if necessary and to take such action as will best aid to avoid collision if the approaching ship fails to keep out of the way.

A civil action to recover damages, subsequent to a collision with a merchant ship is occasionally brought by a yachtsman. In such cases the Court will consider the degree of fault on either side in apportioning damages. A single-handed yachtsman who was asleep in his bunk at the time of collision would almost certainly be held partly to blame on the grounds of failing to keep a proper lookout.

It is conceivable that a single-hander could maintain some degree of almost continuous lookout on a long voyage by catnapping, as suggested by $\mathrm{Mr}$. Hasler, but strict compliance with Rule 5 would be difficult. It is, however, doubtful whether any experienced navigating officer could truthfully claim to have fully complied with the Rules at all times. How many masters would insist on having the whistle sounded at intervals of not more than 2 minutes and proceeding at a moderate speed if fog were to be encountered over a period of several days on a voyage across the North Pacific? How many officers have always sounded the 
appropriate whistle signal when taking avoiding action for a vessel which has been visually sighted?

A ban on the practice of single-handed sailing would make little, if any, contribution to the improvement of safety at sea. The risk of collision in the open sea is almost negligible, especially for small vessels. A survey of world-wide sea collisions over a period of twenty years has revealed only two collisions in the open ocean. In the unlikely event of a collision involving a single-handed yacht it is the yachtsman who would be in danger of losing his life and property and could be held to be at least partly responsible in any subsequent action for damages.

Provided that single-handed races continue to be routed clear of the shipping lanes and competitors are reminded of their obligations under the Rules there would seem to be little point in seeking to impose further restrictions on such events, except perhaps for a limitation on the size of the craft. It is the standard of lookout on merchant ships which presents a far more urgent problem.

\section{from Captain A. Wepster}

The Collision Regulations are part of the Safety of Life at Sea Convention. Safety of life at sea has been and will be the main impetus for maritime safety legislation. Loss of life and more recently, the threat to things living, such as pollution, provide the impulses for new safety rule making. Shipping is no exception to this, proof of which is found in such maritime casualty cases as the Titanic, the Morro Castle and the Torrey Canyon. It may be significant that these three major maritime safety impulses are not in the ship collision category, but are much more specific incidents; hitting an iceberg, a fire, a grounding: the first two accompanied by heavy loss of life, the latter a serious pollution case.

Collisions, even those between two passenger vessels, are not major causes of direct loss of life. A good example of this is the Andrea Doria-Stockholm collision. Out of a total complement of passengers and crew of approximately 2500 people, only some 50 to 60 people lost their lives, with one of the vessels eventually sunk and impossible to salvage.

Collision prevention, of which Rule 5 of the Collision Regulations is a part, is apparently not merely aimed at the prevention of loss of life, but also at the prevention of damage to ship and cargo. As the amounts of dangerous goods carried increase, this damage prevention will also contribute to consequent loss of life prevention. The role dangerous cargoes can play in disastrous loss of life due to collision, was dramatically demonstrated by the accident in Tokyo Bay between the Yoyo Maru 10 and the Pacific Ares.

Turning to single-handed sailing and the Collision Regulations, more specifically Rule 5 of these Regulations, there are various aspects to be considered:

(i) the individual single-handed sailor.

(ii) Single-handed races.

(iii) Safety precautions to be adopted by the race organizers.

(iv) The size and type of the single-handed operated boats, ships and vessels.

(v) The area of operation.

(vi) Other ill-manned small craft operations.

(vii) The attitude of the maritime safety authorities.

If we accept that the main reason for the Collision Regulations is the prevention of loss of life and the threat to things living and if we also for the moment 
simply accept that the responsibility of one's own life is purely one's own affair, then the individual single-hander's problem is reduced to estimating his ability to endanger the lives on board other vessels with which he may come into contact due to his inability to keep at all times a 'proper lookout by sight and hearing'. The ability to endanger others is mainly a matter of speed and size of the singlehander versus the speed and size of his opponents.

Looking at commercial shipping and fishing activities, he will find as opponents in the smallest category approximately 150 -ton vessels with maximum speeds of 10 knots. (This assumption disregards for the time being item no. vi above.) Maritime risk analysis has revealed that it will take at least a 30-ton vessel with a speed of 8 knots to cause damage to these small class vessels to the extent of considerable hull penetration and a possibility of foundering and consequent loss of life.

This leads to the philosophy that the individual single-hander does not pose a problem to society and is merely carrying a responsibility towards himself. However, this philosophy does not release him from Rule 5 of the Collision Regulations nor does it bring him under the category indicated by Cockcroft and Lameyer in their comments to Rule 5 ( 1 ) under Lookout man, where they state: 'On all but the smallest vessels a seaman should normally be posted on lookout duty from dusk to dawn and ... \& \&c.'

In these smallest vessels they imply that keeping an adequate lookout can be part of a multipurpose task; they do not imply that no lookout need be kept.

There also remains the responsibility to other yachtsmen and from the yachtsman to other ill manned small craft. Here the single-hander may fall short of his less isolated and more socially oriented colleagues. Moreover, his desire for isolation and the consequent increase in danger of collision for his colleague yachtsmen and other small craft operators may involve sea rescue organizations.

So for merchant shipping in general there are no serious harmful effects in the individual single-hander and he is welcome to live his life of liberty. However, his fellow yachtsmen have to decide for themselves whether they are willing to accept the sacrifice of additional vigilance in order to protect themselves against the daring, self centred, adventurous single-handed enthusiasts.

A somewhat different problem is posed by single-handed races, especially such mass events as the OSTAR, where a fleet of over a hundred yachts, some of to say the least rather extreme sizes, are simultaneously showered among the existing commercial traffic in the Western area of the British Channel or La Manche. As a sporting event there is undoubtedly something to be said for it, but a very heavy responsibility lies with the organizers, who know that they invoke simultaneous mass violation of Rule 5 of the Collision Regulations.

In addition to the safety precautions and rules already adopted by the organizers of OSTAR every attempt should be made to give ample and timely warning of the event to all shipping in the vicinity of the start and a patrol and warning system should be put into operation to cover an arc up to 600 miles from the start in the direction of the finish. The plans for the race should also be submitted (as in fact they are) to the National Maritime Safety authorities in both the countries of the start and finish.

The precautions to be taken near the finish will, however, be of a different, less exacting nature than those at the time of starting. The distribution in time being such that no appreciable density of blind man's bluff sailors will endanger the destination area. On the other hand their perception, resilience, alertness, 
reaction and other important capabilities and vigilance may have deteriorated under the stress, strain and hardship of a moith or more of loneliness and being buffetted about by wind, sea and swell. These not improbable circumstances may well demand a well organized and immediately available search and rescue capability at the port of destination or in its immediate vicinity.

What has not been taken into consideration is the very remote possibility that a commercial vessel, obliged to take avoiding action for a sleeping single-hander, gets into trouble with another commercial vessel.

Looking at it on a world scale, the whole probability of collision between single handers and commercial shipping is infinitely small. There are approximately 64,000 commercial vessels over 100 GRT in operation, covering approximately 4,000,000,000 miles per annum. The number of single-handed operated yachts will not exceed 500 who on average will together not cover more than 2,000,000 miles per annum.

So commercial ship miles per annum versus single-hander miles per annum is probably better than 2000: I (This merely serves as a numerical value to get a better feeling for the size of the problem.) Another indication of the smallness of the problem is the overall collision rate in one of the busiest shipping areas, the roads and entrance to the Hook of Holland. This collision rate amounts to I collision for I 5,000 ship movements throughout the area.

For the North Atlantic I would reduce that risk by an order of magnitude of 100 and then arrive at a collision rate of 1 in $1,500,000$ ship movements. But since single hander yacht movements are again a fraction of all movements, the collision rate between a commercial vessel and a yacht could further reduce to maybe 1 in 100,000,000 ship movements. All these figures are ultimately based on an operation where vigilance and lookout duty are kept at peak level. For a single hander, who is awake only part of the time, the lookout capability will not be more than 50 per cent which would bring the North Atlantic collision rate for single handers, away from the coastal routes, to something in the order of $I$ in $20,000,000$ ship movements.

Estimating the North Atlantic ship movements at 100,000 per annum, the occurrence of a single-hander-commercial vessel collision would be once in every 200 years. These optimistic figures are based on best guestimates and reality may therefore be quite different, but not so different that a real problem would arise. It is underlined that these figures are very arbitrary; they are only meant to try and demonstrate in a rough manner the kind of probability one may expect. It is better to have some arbitrary numbers available than no figures at all. With no figures at all the discussion could remain wide open in a typical yes-no atmosphere. The figures here presented are in the first place meant to give direction to an eventual discussion. Although feeling and guestimates point in the direction of a very remote possibility that not keeping a lookout will turn into a collision between a single-hander and a commercial vessel, the rules remain the rules, and the authorities the authorities.

It is a fact of life that single-handers will not be able to comply with the Rules, especially Rule 5 dealing with the lookout question. It is clear as a bell that the Authorities will not grant a general exemption to this Rule on behalf of single handed sailing. Such an exception would immediately lead to the necessity for exemptions for those people who earn a living by operating small boats in fishing or other activities and who are often equally unable to keep an adequate lookout as prescribed under Rule 5 of the Collision Regulations. 
Single-handed transatlantic races can however be so organized as indicated above, by choice of area of operation, mainly port of departure and port of destination, and certain precautionary measures regarding the pre-preparedness of participants, warning systems and surveillance, that the single-handed yachts will only constitute a risk towards each other and not towards others such as commercial small vessel operators.

For Imco and the National Maritime Safety Authorities the following attitudes are not possible.

(i) to officially exempt single handers without any restrictions.

(ii) to condone the single hander.

(iii) to negate the fact that single handed sailing means trespassing Rule 5 of the Collision Regulations.

What could be possible as an Imco/National Maritime Safety Authority attitude is :

a. to allow single-handed sailing and races in certain specified areas with low overall traffic densities.

b. To exert influence on the single-handed racing rules with regard to the preparedness of the participants well prior to the starting date.

c. To exert influence with regard to a surveillance and shipping warning system in order to alert shipping. It is realized that especially at night it is a tall order for commercial vessels to watch out for sailing yachts that may not keep a lookout. The best procedure would be to avoid the area where they operate. In reverse the yachtsmen, lookout or no lookout should, if at all possible, avoid the commercial shipping lanes.

\section{Conclusions}

I. The risk for commercial shipping is small.

2. Official authorization to negate Rule 5 of the Collision Regulations should not be expected.

3. All possible measures should be taken by the organizers of single-handed races to avoid interference with commercial shipping.

4. The risk for the single hander is strictly his own affair.

\section{A New Navigation Computer}

\section{Michael Richey}

Through the mediacy of Professor Torao Mozai and the courtesy of Captain T. limura of Omron Tateisi Electronics, Tokyo, I was lent a prototype Omron 1052 NC Astro-navigation computer to evaluate during the course of a singlehanded race in Jester from Newport, Rhode Island, to Bermuda and the subsequent voyage back to England. Although it has been developed as an all-purpose navigation computer, the particular requirements of single-handed oceanic navigation might, it was thought, provide a useful commentary on this kind of instrument; and the environment of a small boat, so close to the sea surface and inevitably 